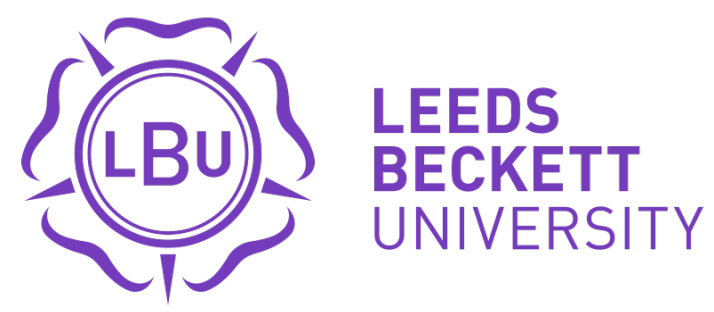

Citation:

Hobbs, M and Griffiths, C and Green, MA and Christensen, A and McKenna, J (2019) Examining longitudinal associations between the recreational physical activity environment, change in body mass index, and obesity by age in 8864 Yorkshire Health Study participants. Social Science and Medicine, 227. pp. 76-83. ISSN 1873-5347 DOI: https://doi.org/10.1016/j.socscimed.2018.06.027

Link to Leeds Beckett Repository record:

https://eprints.leedsbeckett.ac.uk/id/eprint/5299/

Document Version:

Article (Accepted Version)

Creative Commons: Attribution-Noncommercial-No Derivative Works 4.0

The aim of the Leeds Beckett Repository is to provide open access to our research, as required by funder policies and permitted by publishers and copyright law.

The Leeds Beckett repository holds a wide range of publications, each of which has been checked for copyright and the relevant embargo period has been applied by the Research Services team.

We operate on a standard take-down policy. If you are the author or publisher of an output and you would like it removed from the repository, please contact us and we will investigate on a case-by-case basis.

Each thesis in the repository has been cleared where necessary by the author for third party copyright. If you would like a thesis to be removed from the repository or believe there is an issue with copyright, please contact us on openaccess@leedsbeckett.ac.uk and we will investigate on a case-by-case basis. 


\title{
Examining longitudinal associations between the recreational physical activity environment, change in body mass index, and obesity by age in 8864 Yorkshire Health Study participants
}

\author{
1,2Hobbs, M., ${ }^{1}$ Griffiths, C., ${ }^{3}$ Green M., ${ }^{1}$ Christensen, A., ${ }^{1}$ McKenna, J. \\ ${ }^{1}$ School of Sport, Carnegie, Leeds Beckett University, Leeds, LS6 3QT, UK \\ ${ }^{2}$ GeoHealth Laboratory, Geospatial Research Institute, University of Canterbury, Christchurch, New \\ Zealand \\ ${ }^{3}$ School of Environmental Sciences, University of Liverpool, Liverpool, UK
}

\section{Acknowledgements:}

We acknowledge the Ordnance Survey who provided the Points of Interest dataset for the PA environment. We would also like to acknowledge that The Yorkshire Health Study was funded by the NIHR Collaboration for Leadership in Applied Health Research and Care Yorkshire and Humber (NIHR CLAHRC YH). www.clahrc-yh.nihr.ac.uk. The views and opinions expressed are those of the author(s), and not necessarily those of the NHS, the NIHR or the Department of Health.

\section{Corresponding author:}

Matthew Hobbs, m.hobbs@leedstrinity.ac.uk, Leeds Trinity University, LS18 5HD, Leeds, UK

\section{Funding:}

None.

\section{Competing interests:}

None.

Ethical approval:

Approved by Leeds Beckett University Research Ethics.

\section{Authorship:}

All authors made a significant contribution to this paper.

Key words: obesogenic environment; obesity; physical activity; parks; 


\section{Abstract}

The environment may lead to lower body mass index (BMI) and obesity risk by providing opportunities to be physically active. However, while intuitively appealing, associations are often inconsistent in direction and small scale. This longitudinal study examined if change in BMI and obesity was associated with the availability of physical activity (PA) facilities and parks and explored if these associations differed by age. Longitudinal data ( $n=8,864$, aged 18-86 years) were provided at baseline (wave I: 2010 2012) and follow up (wave II: 2013-2015) of the Yorkshire Health Study. BMI was calculated using selfreported height $(\mathrm{cm})$ and weight $(\mathrm{kg})$ (obesity=BMI $\geq 30.00$ ). To define availability, home addresses were geocoded based on postcode zone centroids and neighbourhood was defined as a $2 \mathrm{~km}$ radial buffer. PA facilities were sourced from Ordnance Survey Points of Interest (Pol) and parks were sourced from OpenStreetMap. Environmental data temporally matched individual-level baseline data collection. PA facilities $(b=-0.006[-0.015,0.003])$ and parks $(b=-0.001[-0.015,0.013])$ at baseline were not associated with change in BMI. Change in obesity was unrelated to parks $(\mathrm{OR}=0.994[0.975,1.015])$ and while PA facilities were related $(\mathrm{OR}=0.979[0.965,0.993])$, effects were small. A combined measure of the recreational PA environment including parks and PA facilities was unrelated to change in BMI and obesity. Despite this, statistically significant interactions were found for both PA facilities, parks, and change in obesity by age. Based on the premise that an individual's mobility varies with age, and although effects were small, this offers tentative evidence which suggests it may be useful for policymakers in Public Health and Planning to consider the impact environmental interventions across the life course.

Key words: obesogenic environment; obesity; physical activity; parks 


\section{Introduction}

Obesity prevalence has almost doubled over the past 25 years in the UK with one in four men and women now obese (HSCIC, 2016). Obesity remains a major public health concern due to its association with adverse health conditions (Aune et al., 2016; Calle et al., 2003; Cerhan et al., 2014; Eugenia \& Carmen Rodriguez, 2003; Kitahara et al., 2014). While obesity is multifaceted in aetiology, the physical environment is increasingly recognised as a contributing factor to elevated obesity levels. Furthermore, policy makers are now considering physical environments that promote physical activity (PA) in efforts to tackle obesity (Cavill \& Rutter, 2013). Modifying the physical environment to become more conducive to PA may reduce obesity prevalence (Hill \& Peters, 1998). Some populations may be unfairly predisposed to obesity simply because of the physical environment in which they reside within (Swinburn et al., 1999).

An obesogenic environment is one which promotes obesity by driving an automatic, unconscious influence upon behaviours (Burgoine et al., 2011). The built environment has been shown to be associated with BMI and obesity through metrics such as walkability, land use-mix and residential density (Creatore et al., 2016; Feng, 2010; Halonen et al., 2014; Halonen et al., 2015; Sarkar, 2017; Sarkar et al., 2013; Sarkar et al., 2017). For example, in a review of 132 studies (Leal \& Chaix, 2011), in a large UK based study ( $\mathrm{n=419,000}$ in 22 cities) (Sarkar et al., 2017), and other evidence (Pouliou \& Elliott, 2010; Sallis et al., 2016; Sugiyama et al., 2016), high residential density was associated with lower risk of obesity and lower BMI. This is corroborated by a multi-country study involving 6822 adults across 14 cities, reporting a consistent positive association between net residential density and PA (Sallis et al., 2016). While associations between the built environment and obesity are promising, evidence on the recreational PA environment, which includes the location of parks and PA facilities is more equivocal.

A neighbourhood that has a low availability of recreational physical activity (PA) opportunities such as parks, may also contribute to the extent of the obesogenic environment (Hobbs et al., 2017a; Hobbs et al., 2017c). However, a systematic review showed that only land-use mix and urban sprawl were consistently associated with weight status (Mackenbach et al., 2014). Research linking the recreational PA environment, BMI and obesity is predominantly cross-sectional with much focusing on green space. 
Even so, while several studies have demonstrated associations between green space and obesity, others have produced counterintuitive findings (Lachowycz \& Jones, 2011; Picavet et al., 2016). For instance, an increased level of green space within $125 \mathrm{~m}$ of a home has been shown to be associated with increased odds of obesity (Picavet et al., 2016). There is some evidence that combinations of environmental attributes may be more strongly associated with health-related outcomes than single attributes (Hobbs et al., 2017b; Whitfield et al., 2018). Consequently, a combined measure of the recreational PA environment and the addition of a longitudinal perspective may help uncover meaningful associations between the recreational PA environment and obesity. Furthermore, this association may also vary for different population groups.

While emerging research has hypothesised that the obesogenic environment may exhibit differential effects by socioeconomic status, most literature fails to examine how associations between the environment and obesity varies for different population groups. Although there are some exceptions few studies have explored if the relationship between the PA facilities, parks and obesity differs by age (Burgoine et al., 2016; Burgoine et al., 2017; Mackenbach et al., 2017; Mackenbach et al., 2016). An individual's mobility varies with age, with older adults being less mobile (Chaix et al., 2012; Falkingham et al., 2016; Geist \& McManus, 2008; Hirsch et al., 2014). It is therefore plausible that the immediate residential neighbourhood environment may play a more important role in shaping daily life in individuals who remain closer to home (Falkingham et al., 2016). Our study examines longitudinal associations between the availability of PA facilities and parks in the residential neighbourhood and change in BMI and obesity among adults residing within Yorkshire, in the UK. We extend the evidence base by investigating longitudinal associations and by considering if associations change by age.

\section{Methods}

\section{Study sample}

Study participants in this longitudinal analysis were from the Yorkshire Health Study (YHS) (formerly the South Yorkshire Cohort Study) which has been reported in detail previously (M. Green et al., 2014). In brief, the YHS is an observational cohort study collecting information on the residents (aged 18-89 years) from the Yorkshire and Humberside region in England. It aims to inform National Health Service 
(NHS) and local authority health-related decision making in Yorkshire. Data were collected on current and long-standing health, health care usage and health-related behaviours, with a focus on weight management. Participants in the cohort are older than in the total South Yorkshire population with a higher proportion of females. The majority of participants were also reported being of White ethnicity (94.1\%), which was over representative of the ethnic group (2011 Census; 90.5\%). Ethical clearance was granted by the ethics committee of the Carnegie Faculty, Leeds Beckett University.

Overall, of the 28,806 individuals included in wave one, 18,886 consented to be contacted again and 11,164 returned the longitudinal follow-up $(40.15 \%)$. Reasons for further exclusions were; a location outside Yorkshire $(n=895)$, invalid or biologically implausible height difference $(n=269)$, unable to calculate change in BMI ( $n=689)$, biologically implausible weight values $(n=9)$ and missing either age, gender or ethnicity $(n=438)$. In total, 8,864 individuals provided complete data at baseline [wave one: 2010-2012] and follow up [wave two: 2013-2015] as part of the Yorkshire Health Study (YHS). Importantly, only participants who remained at the same address during the study duration were examined as those who moved were not followed in the longitudinal study. Descriptive statistics for those who completed all waves of data and those who only completed wave one are provided in online supplementary Table S1.

\section{Outcome: body mass index}

Height $(\mathrm{cm})$ and weight $(\mathrm{kg})$ of participants was self-reported. Body mass index (BMI) was then calculated for each participant as weight $(\mathrm{kg}) /$ height $^{2}(\mathrm{~m})$. While it is not a direct measure of body fat, previous research has shown that BMI is useful for understanding obesity in epidemiological studies (M. A. Green, 2015).

\section{Exposure: Physical activity facilities and parks}

The Ordnance Survey (OS), a national mapping agency, provided PA facility locations for 2013 (easting, northing). The Point of Interest (Pol) dataset is suggested as an accurate source of secondary data ( $\mathrm{E}$. Wilkins et al., 2017a). Classifications were defined based on 18 proprietary classifications related to PA i.e. "Athletics Facilities" but not parks. Supplement 5 provides a full breakdown of classifications used in accordance with the Geo-FERN reporting framework (E. L. Wilkins et al., 2017b). Parks were sourced 
in 2013 from ‘OpenStreetMap' and defined as an open and accessible green area for recreation typically open to the public that is in a town or city.

\section{Neighbourhood}

To define availability, home addresses were geocoded based on postcode zone centroids. Neighbourhood was then defined as a $2 \mathrm{~km}$ radial buffer centred on the home postcode. This gives an approximate measure of availability by car and previous analyses on the same sample have shown little difference in associations when using $1600 \mathrm{~m}$ radial buffers which may better reflect availability when walking (Smith et al., 2010). In this instance the use of a $2 \mathrm{~km}$ buffer encapsulates the potential for both walking and driving behaviours that are commonplace in this UK population. PA facilities within each $2 \mathrm{~km}$ buffer were counted using a point in polygon analysis. Any park that was within or had a boundary that overlapped the 2km buffer, was linked using ArcGIS V10.2.2 (ESRI Inc., Redlands, CA).

\section{Covariates}

Covariates were identified based on previous literature but was restricted by what was available within the Yorkshire Health Study. Age, gender (male/female), ethnicity (White-British and other), education level (none=no qualification; moderate=school, college or other; high=university education) area-level deprivation score (Index of Multiple Deprivation; IMD 2015) and population density were included in all models as covariates. These were each included due to their associations to body weight. IMD provides a multidimensional measure of deprivation (based on 37 separate indicators, organised across seven distinct domains of; income deprivation; employment deprivation; health deprivation and disability; education, skills and training deprivation; crime; barriers to housing and services; and living environment deprivation) and is commonly used by Local Governments in the UK. IMD scores were assigned to the lower super-output area (LSOA) of each individual, as determined by their geocoded postcode. A higher IMD deprivation score equates to a higher level of deprivation (Department for Communities and Local Government, 2015).

\section{Statistical analysis}

Linear regression $(\mathrm{b}[95 \% \mathrm{Cl}])$ models were used to investigate if $\mathrm{BMI}$ changed over the two waves of data collection in relation to the PA environment. Logistic regression (Odds Ratio [95\% Cl]) was used 
to investigate if obesity prevalence changed over the two waves in relation to the PA environment. Both a continuous exposure of count and quartiles were used to represent PA facilities and parks. Thresholds for defining combined PA environments were deduced based on the count of PA facilities and parks within home neighbourhoods. Furthermore, a combined environment was defined as "Favourable for PA" if it had $\geq 1$ PA facility and $\geq 1$ park, "Unfavourable for PA" was defined as having no PA facility and no park. Other combinations, for instance if only parks or PA facilities were available, were then defined as "Moderately favourable for PA". For associations with the combined PA environment "unfavourable PA environments" were used as the reference category. Due to the high statistical power in the dataset and assumption that data were missing at random (Supplement 1) missing data were dealt with by listwise deletion. Sensitivity analyses were also undertaken using multilevel models to examine whether the change in BMI differed dependent on the number of parks of PA facilities at baseline. An interaction between each availability measure (PA facilities and parks) and time was fitted. As consistent with previous literature this implies that main effects should not be interpreted without consideration of their combined effect (Lamb et al., 2017). The multilevel models included both a random intercept to allow each participant to have their own unique intercept. A progression to a random slope to allow each individual to have their own rate of change did not improve the model. All models adjusted for covariates. When associations were investigated by age, in addition to an interaction term being fitted, to aid interpretation of these models, we also calculated the marginal effect (i.e. predicted probability) of the change in the outcome by age, for each category of the environmental exposure. All analyses were conducted in STATA MP 14.2.

\section{Results}

\section{Descriptive statistics}

As outlined in Table 1, average BMI did not substantively change over the waves from baseline at 26.42 $\mathrm{kg} / \mathrm{m} 2(\mathrm{SD}=4.71)$ to follow up at $26.41 \mathrm{~kg} / \mathrm{m} 2(\mathrm{SD}=4.72)$. The number of obese individuals decreased slightly from $n=1646(18.6 \%)$ at baseline to $1622(18.3 \%)$ at three-year follow up. In this large sample ( $n=8864)$ of UK adults, the mean number of PA facilities available at baseline was $7.84(S D=4.90)$ and 2.68 parks $(S D=3.37)$ within a $2 \mathrm{~km}$ radial buffer. Overall, only $23.87 \%$ of individuals resided within a favourable environment, while $35.47 \%$ of individuals resided within an unfavourable environment with no park or PA facility availability. 


\section{Availability of parks and physical activity facilities at baseline and change in body mass index} Two separate linear regression models $(\mathrm{b}[95 \% \mathrm{Cl}])$ investigated between PA facilities, parks and change in BMI. Two separate logistic regression models (OR $[95 \% \mathrm{Cl}])$ investigated the relationship between PA facilities, parks and change in obesity. Overall, there was little evidence to suggest that the PA facilities or parks at baseline predicted change in BMI (Table 2). After adjustment for covariates, the count of PA facilities was not associated with change in BMI $(b=-0.006[-0.015,0.003])$. Similarly, the count of parks was not associated with change in BMI $(b=-0.001[-0.015,0.013])$. Moreover, the count of parks was also unrelated to change in obesity prevalence (OR=0.994 $[0.975,1.015])$. While change in obesity prevalence was associated with the count of PA facilities (OR=0.979 $[0.965,0.993])$, effects were small. There was also no association between change in BMI and obesity when considering associations with the combined environment (Supplement 6).

\section{INSTER TABLE 2 HERE}

Results including an interaction effect between PA facilities and age, and parks and age, are displayed in Table 3. Again, two separate linear regression models (b [95\% Cl]) investigated between PA facilities, parks and change in BMI. Two separate logistic regression models $(\mathrm{OR}[95 \% \mathrm{Cl}])$ investigated the relationship between PA facilities, parks and change in obesity. There was no association for change in BMI for PA facilities and parks by age. This is perhaps not surprising given that BMI changed over little over the two waves. However, significant interactions were revealed for both PA facilities and parks by age, for change in obesity. This suggests that considering both age and aspects of the PA environment together are important for determining change in obesity. The interaction is only apparent in those with the highest availability of PA facilities and parks. For PA facilities, relative to those with the lowest availability, a small effect was seen by age for change in obesity $(\mathrm{OR}=1.019[1.006,1.031])$. A high availability of PA facilities was particularly beneficial in early adulthood. Similarly, a very small effect was seen for those with the highest availability of parks (OR=1.016 [1.005, 1.027]), again with the lowest risk of obesity at both waves for those in early adulthood. This interaction effect is plotted visually for ease of interpretation within Figure 4A and 4B. Each plot demonstrates a positive relationship with 
age and risk of obesity. While at younger ages, risk of obesity was much lower for individuals with the greatest access than all other exposures, the probability of obesity increased with age so that by ages 60 onwards there was little difference in the risk of obesity between exposures. There was also no association between change in BMI and obesity when considering associations with the combined environment by age (Supplement 6).

\section{INSERT TABLE 3 HERE}

\section{Sensitivity analyses}

Three sensitivity analyses were conducted. First, multilevel models that accounted for the clustered nature of measurements within individuals demonstrated substantively the same findings and capturing change in BMI (Supplement 2). We found no evidence of an interaction between time and the baseline number of PA facilities $2 \mathrm{~km}$ buffer $(b=-0.002[-0.010,0.006], p>0.05)$. Second, associations differed very little when comparing different definitions of neighbourhood when using different radial buffer sizes $(1.6 \mathrm{~km}, 2 \mathrm{~km})$ (Supplement 3). Third, when interactions were examined by continuous exposure variables of PA facilities, a significant interaction was again noted (Supplement 4). Categorical exposure variables for both PA facilities and parks are presented for ease of interpretation.

\section{INSERT FIGURE 4 HERE}

\section{Discussion}

This study used a large longitudinal sample to relate PA facility and park availability within the residential neighbourhood, change in body mass index (BMI) and change in obesity prevalence. Both PA facilities and parks at baseline were unrelated to change in BMI. However, effects were noted for change in obesity but only for count of PA facilities not count of parks. A combined measure of the recreational PA environment including parks and PA facilities was also unrelated to change in BMI and obesity. Evidence was advanced by considering if age was important in determining the relationship between the environment and change in obesity. This is one of the first studies internationally to consider such an association by age due to the hypothesised change in mobility as adult's age (Falkingham et al., 2016). Our results highlighted an interaction for those with the highest count of both PA facilities and parks. Based on the premise that an individual's mobility varies with age, and although effects were 
small, this offers tentative evidence which suggests it may be useful for policymakers in Public Health and Planning to consider the impact of environmental interventions across the life course.

A large body of literature has failed to identify consistent associations between aspects of the recreational PA environment and weight-related outcomes (Mackenbach et al., 2014). Longitudinal findings in this study confirmed these inconsistent findings demonstrating no substantive association between PA facilities, parks or a combined measure of the recreational PA environment and change in BMI. Findings within this longitudinal study are also consistent with more recent evidence that showed substantively no association between green spaces, parks of the availability of PA facilities and BMI (Droomers et al., 2016; Lachowycz \& Jones, 2011). A recent quasi-experimental study for instance showed no short term effects on PA among adults from improvements in green space in deprived neighbourhoods (Droomers et al., 2016). It is important to note that evidence relating aspects of the recreational PA environment and $\mathrm{BMI}$ is rapidly developing and the current absence of evidence, may not necessarily mean an evidence of absence (Panter et al., 2017). A recent network analysis for instance, illustrates that the composition of the PA environment research network is highly US-centric and largely cross-sectional (Harris et al., 2013). Moreover, the evidence base is largely in the discovery phase. This study therefore adds important UK-based longitudinal evidence.

This study takes a more sophisticated approach to studying the relationship between the recreational PA environment and body weight. It takes into account how the physical environment may matter for some populations, but not others (Swinburn \& Egger, 2002). We respond to calls from key authors to examine 'hidden interactions' where the main effect of the environment-outcome association may not statistically significant but, when stratified by different subgroups, associations may be present (Mackenbach et al., 2016). In this study, age was shown to be important in revealing associations with change in obesity, whereby younger adults were less likely to be obese in neighbourhoods with a high count of PA facilities and parks (Figure 4). Research has demonstrated that for older adults, the immediate neighbourhood environment is thought to play a more important role in shaping daily life than younger adults who may have different mobility patterns (Falkingham et al., 2016). However, this study suggests that younger adults may also respond more positively to the presence of PA facilities or parks. Future research, rather than merely controlling for age, may benefit from trying to stratify by age group 
and understanding why age may interact with environmental exposures. While our results are mainly descriptive and preliminary, it is reasonable given the previous evidence of change in mobility patterns (Falkingham et al., 2016), to suggest that younger, middle aged and older adults may interact differently with their recreational PA environment which surrounds their home (Feng, 2010; Panter et al., 2017). Extending this approach to understand how the PA environment impacts on risk of obesity over the life course is also a logical extension (Pearce et al., 2016).

\section{Implications for policy and practice}

Regular PA is a contributor to energy balance and weight maintenance (Johns et al., 2014; Swift et al., 2014). Consequently, an environment where places to be active are available is therefore hypothesised to contribute to increased PA, and thus reduced BMI. However, despite being a key element of the National Planning Policy Framework within the UK (Department for Communities and Local Government, 2012; Department of Communities \& Local Government, 2014) and a priority initiative for the Town and Country Planning Association within the UK (Town and Country Planning Association, 2014, 2016), less evidence considers the association between the recreational PA environment with much evidence focusing on the food environment in particular, restricting the proliferation of fast-food outlets. While effects were small, for policymakers such as planners and Public Health officials, the longitudinal evidence within this study has important direct relevance.

Whilst we do not refute the importance of availability of PA facilities and parks, this study reinforces previous research that suggests efforts to tackle increases in BMI may have little effect if regulation focuses on geographical restriction alone. Policy makers may however focus on how the PA facilities and parks are linked to change in obesity over time for different age groups. For instance, the notion that designing an active and healthy environment differs by age is tentatively supported by results in this study. While effects in this study were small they indicated that the association between PA facilities, parks and change in obesity differed by age. Consequently, such conclusions support previous evidence which suggests that the physical environment may matter more for some populations, than others (Burgoine et al., 2016; Burgoine et al., 2017; Hobbs et al., 2017b). Understanding how different population groups may respond to different policies is an important future direction for both researchers and policy makers. Perhaps more importantly, ignoring the broader context in which the environment 
operates, as well as how it interacts with individual-level factors such as age or socioeconomic status, may be limiting the impact of such potential environmental-level policies.

\section{Limitations}

Height and weight were self-reported and while such measures may be useful at a population level, the self-reported nature of this measure may have introduced some bias into our study. For instance, in a large sample of UK adults $(n=4808)$ spearman rank correlations between self-reported and measured height, weight and BMI were high $(r>0.9, p<0.0001)$ however, weight was underestimated by a mean of $1.85(1.72-1.99) \mathrm{kg}$ in men and $1.40(1.31-1.49) \mathrm{kg}$ in women (Spencer et al., 2002). While environmental- and individual-level data were matched in terms of timing at baseline, time-varying environmental data were not available limiting the longitudinal nature of our study. As eloquently discussed by Norman (2018) it would have also been beneficial to have a longer follow up period and time-varying socio-demographic characteristics at the area- and individual-level. For instance, education was only collected at baseline which does not truly account for change over time (although we do not expect major changes). We also only have data for two waves of data collection, and were unable to investigate how the environment influences body weight for individuals across their life course which may help to gain a better understanding of how the environment influences age (Pearce et al., 2016). Self-selection bias, where individuals self-select into environments due to migration patterns, cannot be ruled out as a factor affecting our analyses since individuals who moved neighbourhoods were not followed up in the second wave of the YHS (Boone-Heinonen et al., 2011; Boone-Heinonen et al., 2010).

The study's definition of neighbourhood assumed that participants use parks and PA facilities within $2 \mathrm{~km}$ of their home. Although postcodes in the UK allow for relatively precise geocoding, each postcode area contains 15 addresses on average which may lead to some inaccuracies in geocoding. Moreover, while research suggests that $\mathrm{POI}$ is an accurate source of environmental data (Burgoine \& Harrison, 2013; E. Wilkins et al., 2017a), we were unable to ground truth these locations across the study region. Finally, participants in the YHS were over-representative of older adults, females, and non-white ethnicities relative to the actual population limiting the generalisability of our findings. In addition, this 
study only addressed the recreational PA environment and broader attributes such as walkability or the quality of such features may be important future considerations to capture.

\section{Conclusion}

Our results provide novel UK-based longitudinal evidence that represents one of the first papers internationally to consider the interplay of age and the recreational PA environment when investigating associations with change in BMI and obesity. In summary, whilst overall findings show substantively no association between the availability of PA facilities, parks and change in BMI, they are important and advance the cross-sectional study designs that dominate current evidence. On the contrary, associations between the count of parks and PA facilities and change in obesity differed somewhat by age. This was especially true for those with the highest availability of PA facilities and parks. For policymakers in Planning and Public Health, this study offers tentative evidence that supports previous research which suggests that the environment may matter more for some populations, than others. Accounting for the interaction between individual-level factors such as age and the environment may be important in revealing longitudinal associations with change in obesity and when designing healthy environments for different populations. 


\section{References}

Aune, D., Sen, A., Prasad, M., Norat, T., Janszky, I., Tonstad, S., et al. (2016). BMI and all cause mortality: systematic review and non-linear dose-response meta-analysis of 230 cohort studies with 3.74 million deaths among 30.3 million participants. BMJ, 353.

Boone-Heinonen, J., Gordon-Larsen, P., Guilkey, D.K., Jacobs, D.R., \& Popkin, B.M. (2011). Environment and physical activity dynamics: The role of residential self-selection. Psychology of Sport and Exercise, 12, 19.

Boone-Heinonen, J., Guilkey, D.K., Evenson, K.R., \& Gordon-Larsen, P. (2010). Residential self-selection bias in the estimation of built environment effects on physical activity between adolescence and young adulthood. International Journal of Behaviour, Nutrition and Physical Activity, 7, 1.

Burgoine, T., Alvanides, S., \& Lake, A.A. (2011). Assessing the obesogenic environment of North East England. Health Place, 17, 738-747.

Burgoine, T., Forouhi, N.G., Griffin, S.J., Brage, S., Wareham, N.J., \& Monsivais, P. (2016). Does neighborhood fast-food outlet exposure amplify inequalities in diet and obesity? A cross-sectional study. The American Journal of Clinical Nutrition, 103, 1540.

Burgoine, T., \& Harrison, F. (2013). Comparing the accuracy of two secondary food environment data sources in the UK across socio-economic and urban/rural divides. International Journal of Health Geographics, 12, 2.

Burgoine, T., Mackenbach, J., Lakerveld, J., Forouhi, N., Griffin, S., Brage, S., et al. (2017). Interplay of Socioeconomic Status and Supermarket Distance Is Associated with Excess Obesity Risk: A UK Cross-Sectional Study. Int J Environ Res Public Health, 14, 1290.

Calle, E., Rodriguez, C., Walker-Thurmond, K., \& Thun, M. (2003). Overweight, Obesity, and Mortality from Cancer in a Prospectively Studied Cohort of U.S. Adults. New England Journal of Medicine, 348, 1625-1638.

Cavill, N., \& Rutter, H. (2013). Healthy people, healthy places briefing: obesity and the environment: increasing physical activity and active travel. London: Public Health England.

Cerhan, J.R., Moore, S.C., Jacobs, E.J., Kitahara, C.M., Rosenberg, P.S., Adami, H.O., et al. (2014). A pooled analysis of waist circumference and mortality in 650,000 adults. Mayo Clin Proc, 89, 335-345.

Chaix, B., Kestens, Y., Perchoux, C., Karusisi, N., Merlo, J., \& Labadi, K. (2012). An Interactive Mapping Tool to Assess Individual Mobility Patterns in Neighborhood Studies. American Journal of Preventative Medicine, 43, 440.

Creatore, M.I., Glazier, R.H., Moineddin, R., \& et al. (2016). Association of neighborhood walkability with change in overweight, obesity, and diabetes. JAMA, 315, 2211-2220.

Department for Communities and Local Government (2012). National planning policy framework. London: Department for Communities and Local Government.

Department for Communities and Local Government (2015). Neighbourhood statistics: The English Indices of Deprivation 2015. London: Department for Communities and Local Government,.

Department of Communities \& Local Government (2014). National Planning Practice Guidance; Health and Wellbeing. London: DCLG.

Droomers, M., Jongeneel-Grimen, B., Kramer, D., de Vries, S., Kremers, S., Bruggink, J.-W., et al. (2016). The impact of intervening in green space in Dutch deprived neighbourhoods on physical activity and general health: results from the quasiexperimental URBAN40 study. Journal of Epidemiology and Community Health, 70, 147-154.

Eugenia, C., \& Carmen Rodriguez, M.D., M.P.H., Kimberly Walker-Thurmond, B.A., and Michael J. Thun, M.D. (2003). Overweight, Obesity, and Mortality from Cancer in a Prospectively Studied Cohort of U.S. Adults. New England Journal of Medicine, 348, 1625-1638. 
Falkingham, J., Sage, J., Stone, J., \& Vlachantoni, A. (2016). Residential mobility across the life course: Continuity and change across three cohorts in Britain. Advances in Life Course Research, 30, 111.

Feng, J. (2010). The built environment and obesity: a systematic review of the epidemiologic evidence. Health and Place, 16.

Geist, C., \& McManus, P.A. (2008). Geographical mobility over the life course: Motivations and implications. Population Space and Place, 14.

Green, M., Li, J., Relton, C., Strong, M., Kearns, B., Wu, M., et al. (2014). Cohort Profile: The Yorkshire Health Study. International Journal of Epidemiology, doi: 10.1093/ije/dyu1121.

Green, M.A. (2015). Do we need to think beyond BMI for estimating population-level health risks? Journal of Public Health.

Halonen, J., Kivimaki, M., Pentti, J., Stenholm, S., Kawachi, I., Subramanian, S., et al. (2014). Green and blue areas as predictors of overweight and obesity in an 8-year follow-up study. Obesity, 22, 1910.

Halonen, J., Stenholm, S., Kivimäki, M., Pentti, J., Subramanian, S., Kawachi, I., et al. (2015). Is change in availability of sports facilities associated with change in physical activity? A prospective cohort study. Preventive Medicine, 73, 10.

Harris, J.K., Lecy, J., Hipp, J.A., Brownson, R.C., \& Parra, D.C. (2013). Mapping the development of research on physical activity and the built environment. Preventive Medicine, 57, 533.

Hill, J., \& Peters, J. (1998). Environmental contributions to the obesity epidemic. Science, 280, 1371-1374.

Hirsch, J., Winters, M., Clarke, P., \& McKay, H. (2014). Generating GPS activity spaces that shed light upon the mobility habits of older adults: a descriptive analysis. International Journal of Health Geographics, 13, 51-64.

Hobbs, M., Green, M., Griffiths, C., Jordan, H., Saunders, J., Grimmer, H., et al. (2017a). Access and quality of parks and associations with obesity: A cross-sectional study. SSM - Population Health, 3, 722.

Hobbs, M., Griffiths, C., Green, M., Jordan, H., Saunders, J., \& McKenna, J. (2017b). Associations between the combined physical activity environment, socioeconomic status, and obesity: a cross-sectional study. Perspect Public Health, 1757913917748353.

Hobbs, M., Griffiths, C., M, G., Jordan, H., Saunders, J., \& McKenna, J. (2017c). Neighbourhood typologies and associations with body mass index and obesity: a cross-sectional study Preventive Medicine.

HSCIC (2016). Statistics on Obesity, Physical Activity and Diet: England 2016. London: The Health and Social Care Information Centre (HSCIC), .

Johns, D.J., Hartmann-Boyce, J., Jebb, S.A., \& Aveyard, P. (2014). Diet or Exercise Interventions vs Combined Behavioral Weight Management Programs: A Systematic Review and Meta-Analysis of Direct Comparisons. Journal of the Academy of Nutrition and Dietetics, 114, 1557.

Kitahara, C., A, F., Berrington de Gonzalez, A., Bernstein, L., Brotzman, M., Maclnnis, R., et al. (2014). Association between Class III Obesity (BMI of $40-59 \mathrm{~kg} / \mathrm{m} 2$ ) and Mortality: A Pooled Analysis of 20 Prospective Studies. PLoS Med, 11, e1001673.

Lachowycz, K., \& Jones, A. (2011). Greenspace and obesity: a systematic review of the evidence. Obesity Reviews, 12, 183.

Lamb, K.E., Thornton, L.E., Olstad, D.L., Cerin, E., \& Ball, K. (2017). Associations between major chain fast-food outlet availability and change in body mass index: a longitudinal observational study of women from Victoria, Australia. BMJ Open, 7.

Leal, C., \& Chaix, B. (2011). The influence of geographic life environments on cardiometabolic risk factors: a systematic review, a methodological assessment and a research agenda. Obesity Reviews, 12, 217. 
Mackenbach, J., Burgoine, T., Lakerveld, J., Forouhi, N.G., Griffin, S.J., Wareham, N.J., et al. (2017). Accessibility and Affordability of Supermarkets: Associations With the DASH Diet. American Journal of Preventative Medicine.

Mackenbach, J., Lakerveld, J., Van Lenthe, F.J., Teixeira, P.J., Compernolle, S., De Bourdeaudhuij, I., et al. (2016). Interactions of individual perceived barriers and neighbourhood destinations with obesity-related behaviours in Europe. Obesity Reviews, 17, 68.

Mackenbach, J., Rutter, H., Compernolle, S., Glonti, K., Oppert, J.-M., Charreire, H., et al. (2014). Obesogenic environments: a systematic review of the association between the physical environment and adult weight status, the SPOTLIGHT project. BMC Public Health, 14, 233.

Norman, P.D. (2018). Clarity in research frameworks for studying 'health selective migration'. Journal of Epidemiology and Community Health, 72, 449-450.

Panter, J., Guell, C., Prins, R., \& Ogilvie, D. (2017). Physical activity and the environment: conceptual review and framework for intervention research. International Journal of Behaviour, Nutrition and Physical Activity, 14, 156.

Pearce, J., Shortt, N., Rind, E., \& Mitchell, R. (2016). Life Course, Green Space and Health: Incorporating Place into Life Course Epidemiology. Int J Environ Res Public Health, 13, 331.

Picavet, H.S.J., Milder, I., Kruize, H., de Vries, S., Hermans, T., \& Wendel-Vos, W. (2016). Greener living environment healthier people?: Exploring green space, physical activity and health in the Doetinchem Cohort Study. Preventive Medicine, 89, 7.

Pouliou, T., \& Elliott, S.J. (2010). Individual and socio-environmental determinants of overweight and obesity in Urban Canada. Health Place, 16, 389.

Sallis, J.F., Cerin, E., Conway, T.L., Adams, M.A., Frank, L.D., \& Pratt, M. (2016). Physical activity in relation to urban environments in 14 cities worldwide: a cross-sectional study. Lancet, 387.

Sarkar, C. (2017). Residential greenness and adiposity: Findings from the UK Biobank. Environment International, 106, 1.

Sarkar, C., Gallacher, J., \& Webster, C. (2013). Built environment configuration and change in body mass index: the Caerphilly Prospective Study (CaPS). Health and Place, 19, 33.

Sarkar, C., Webster, C., \& Gallacher, J. (2017). Association between adiposity outcomes and residential density: a full-data, cross-sectional analysis of 419562 UK Biobank adult participants. The Lancet Planetary Health, 1, e277.

Smith, G., Gidlow, C., Davey, R., \& Foster, C. (2010). What is my walking neighbourhood? A pilot study of English adults' definitions of their local walking neighbourhoods. International Journal of Behavioral Nutrition and Physical Activity, 7, 34.

Spencer, E.A., Appleby, P.N., Davey, G.K., \& Key, T.J. (2002). Validity of self-reported height and weight in 4808 EPIC-Oxford participants. Public Health Nutrition, 5, 561.

Sugiyama, T., Niyonsenga, T., Howard, N.J., Coffee, N.T., Paquet, C., Taylor, A.W., et al. (2016). Residential proximity to urban centres, local-area walkability and change in waist circumference among Australian adults. Preventive Medicine, 93, 39.

Swift, D.L., Johannsen, N.M., Lavie, C.J., Earnest, C.P., \& Church, T.S. (2014). The Role of Exercise and Physical Activity in Weight Loss and Maintenance. Progress in cardiovascular diseases, 56, 441.

Swinburn, B., \& Egger, G. (2002). Preventive strategies against weight gain and obesity. Obesity Reviews, 3, 289.

Swinburn, B., Egger, G., \& Raza, F. (1999). Dissecting obesogenic environments: the development and application of a framework for identifying and prioritising environmental interventions for obesity. Preventive Medicine, 29, 563.

Town and Country Planning Association (2014). Planning healthy weight environments - a TCPA reuniting health with planning project. London: Public Health England.

Town and Country Planning Association (2016). Building the foundations - tackling obesity through planning and development. London: Public Health England. 
Whitfield, G.P., Carlson, S.A., Ussery, E.N., Watson, K.B., Adams, M.A., James, P., et al. (2018). Environmental Supports for Physical Activity, National Health Interview Survey-2015. Am J Prev Med, 54, 294-298.

Wilkins, E., Morris, M., Radley, D., \& Griffiths, C. (2017a). Validation of two secondary sources of food environment data against street audits in England. The Society For Social Medicine. Manchester, UK: Journal of Epidemiology and Community Health Wilkins, E.L., Morris, M.A., Radley, D., \& Griffiths, C. (2017b). Using Geographic Information Systems to measure retail food environments: Discussion of methodological considerations and a proposed reporting checklist (Geo-FERN). Health and Place, 44, 110. 
Table 1 - Descriptive characteristics of participants in the Yorkshire Health Study ( $n=8864)$

\begin{tabular}{|c|c|c|}
\hline Variable & $\begin{array}{l}\text { Wave one } \\
\text { [2010-2012] }\end{array}$ & $\begin{array}{l}\text { Wave two } \\
\text { [2013-2015] }\end{array}$ \\
\hline \multicolumn{3}{|l|}{ Outcome } \\
\hline \multicolumn{3}{|l|}{ Body mass index $\left(\mathrm{kg} / \mathrm{m}^{2}\right)$} \\
\hline Mean (SD) & $26.42(\mp 4.71)$ & $26.41(\mp 4.72)$ \\
\hline Minimum, maximum & $15.06,62.00$ & $15.06,62.00$ \\
\hline Obese $(\mathrm{n}(\%))$ & $1646(18.6)$ & $1622(18.3)$ \\
\hline \multicolumn{3}{|l|}{ Exposure } \\
\hline \multicolumn{3}{|l|}{ Physical activity facilities } \\
\hline Mean (SD) & $7.84(4.90)$ & - \\
\hline Minimum, maximum & 0,31 & - \\
\hline \multicolumn{3}{|l|}{ Parks } \\
\hline Mean (SD) & $2.68(\mp 3.37)$ & - \\
\hline Minimum, maximum & 0,22 & - \\
\hline \multicolumn{3}{|l|}{ Combined environment ( $\mathrm{n}(\%))$} \\
\hline Unfavourable environment & $3144(35.47)$ & - \\
\hline Moderately favourable & 3604 (40.66) & - \\
\hline Favourable environment & $2116(23.87)$ & - \\
\hline \multicolumn{3}{|l|}{ Covariates } \\
\hline Age & 57.42 (干14.27) & - \\
\hline \multicolumn{3}{|l|}{ Education (n (\%)) } \\
\hline Low (no qualification) & $1793(20.2)$ & - \\
\hline Moderate (school, college, other) & $4608(52.0)$ & - \\
\hline High (university) & $2463(27.8)$ & - \\
\hline \multicolumn{3}{|l|}{ Gender } \\
\hline Male & $3818(43.1)$ & - \\
\hline Female & $5046(56.9)$ & - \\
\hline \multicolumn{3}{|l|}{ Population Density } \\
\hline Low & - & 3007 (33.9) \\
\hline Moderate & - & $2908(32.8)$ \\
\hline High & - & 2949 (33.3) \\
\hline \multicolumn{3}{|l|}{ Area-level deprivation } \\
\hline Q1 & - & 2337 (26.4) \\
\hline Q2 & - & $2172(24.5)$ \\
\hline Q3 & - & $2221(25.1)$ \\
\hline Q4 & - & $2134(24.1)$ \\
\hline
\end{tabular}


Table 2 - Findings from linear and logistic regression model investigating the association between change in BMI and the availability of PA facilities and parks at baseline

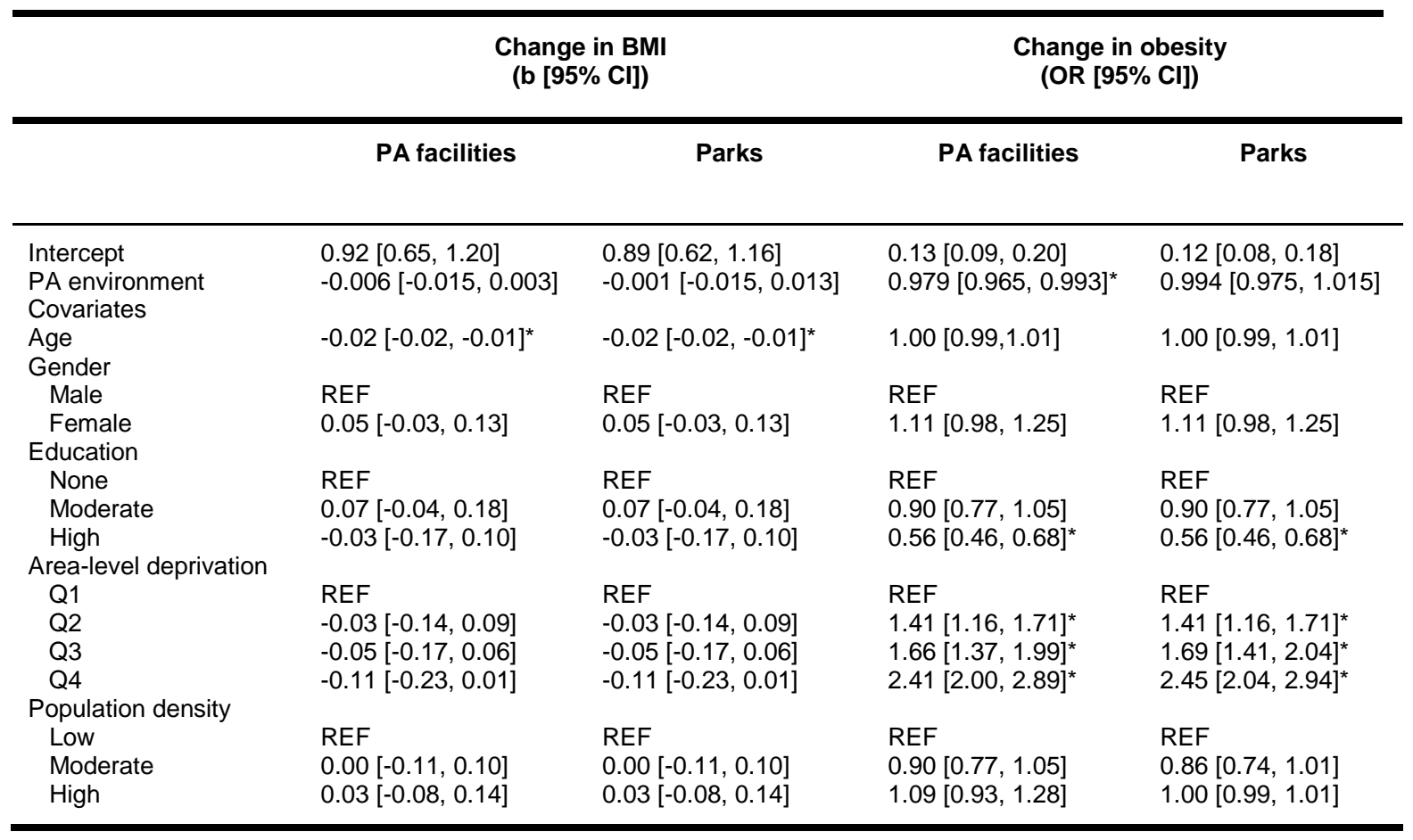


Table 3 - Findings from linear and logistic regression model investigating the association between change in BMI and obesity, the availability of PA facilities and parks at baseline, and interactions by age

\begin{tabular}{|c|c|c|c|c|}
\hline & \multicolumn{2}{|c|}{$\begin{array}{c}\text { Change in BMI } \\
\text { (b }[95 \% \mathrm{Cl}])\end{array}$} & \multicolumn{2}{|c|}{$\begin{array}{l}\text { Change in obesity } \\
\text { (OR [95\% Cl]) }\end{array}$} \\
\hline & PA facilities & Parks & PA facilities & Parks \\
\hline Intercept & $1.00[0.611,1.38]$ & $0.91[0.60,1.23]$ & $0.20[0.07,0.56]$ & $0.15[0.10,0.25]$ \\
\hline \multicolumn{5}{|c|}{ Environment * age } \\
\hline Q1 & REF & REF & REF & REF \\
\hline Q2 & $0.003[-0.004,0.012]$ & $-0.008[-0.017,0.001]$ & $1.009[0.997,1.021]$ & $1.004[0.993,1.014]$ \\
\hline Q3 & $-0.003[-0.012,0.004]$ & $0.005[-0.001,0.011]$ & $1.008[0.996,1.020]$ & $1.016[1.005,1.027]^{\star}$ \\
\hline Q4 & $0.005[-0.003,0.013]$ & - & $1.019[1.006,1.031]^{\star}$ & - \\
\hline \multicolumn{5}{|l|}{ Environment } \\
\hline Q1 & REF & REF & REF & REF \\
\hline Q2 & $-0.26[-0.72,0.21]$ & $0.42[-0.10,0.95]$ & $0.53[0.26,1.08]$ & $0.85[0.45,1.58]$ \\
\hline Q3 & $0.14[-0.34,0.62]$ & $-0.24[-0.60,0.12]$ & $0.56[0.27,1.12]$ & $0.38[0.46,0.68]$ \\
\hline Q4 & $-0.63[-0.83,0.10]$ & - & $0.27[0.13,0.57]^{*}$ & - \\
\hline \multicolumn{5}{|l|}{ Covariates } \\
\hline Age & $-0.017[-0.023,-0.011]$ & $-0.016[-0.020,-0.012]$ & $0.995[0.987,1.003]$ & $0.999[0.993,1.005]$ \\
\hline \multicolumn{5}{|l|}{ Gender } \\
\hline Male & REF & REF & REF & REF \\
\hline Female & $0.05[-0.03,0.13]$ & $0.05[-0.03,0.13]$ & $1.11[0.98,1.25]$ & $1.11[0.98,1.25]$ \\
\hline \multicolumn{5}{|l|}{ Education } \\
\hline None & REF & REF & REF & REF \\
\hline Moderate & $0.07[-0.04,0.18]$ & $0.07[-0.03,0.12]$ & $0.90[0.76,1.05]$ & $0.91[0.78,1.06]$ \\
\hline High & $-0.04[-0.17,0.10]$ & $-0.03[-0.16,0.09]$ & $0.56[0.45,0.68]^{*}$ & $0.56[0.46,0.69]^{\star}$ \\
\hline \multicolumn{5}{|c|}{ Area-level deprivation } \\
\hline Q1 & REF & REF & REF & REF \\
\hline Q2 & $-0.02[-0.14,0.09]$ & $-0.03[-0.14,0.09]$ & $1.40[1.16,1.71]^{\star}$ & $1.41[1.16,1.71]^{\star}$ \\
\hline Q3 & $-0.05[-0.17,0.06]$ & $-0.04[-0.16,0.07]$ & $1.65[1.37,1.99]^{*}$ & $1.68[1.39,2.02]^{\star}$ \\
\hline Q4 & $-0.12[-0.23,0.00]$ & $-0.10[-0.22,0.01]$ & $2.38[1.98,2.86]^{*}$ & $2.40[1.99,2.89]^{*}$ \\
\hline \multicolumn{5}{|c|}{ Population density } \\
\hline Low & REF & REF & REF & REF \\
\hline Moderate & $0.00[-0.10,0.10]$ & $-0.02[-0.11,0.09]$ & $0.89[0.76,1.04]$ & $0.85[0.73,1.01]$ \\
\hline High & $0.03[-0.08,0.14]$ & $-0.01[-0.11 .0 .10]$ & $1.08[0.92,1.27]$ & $1.00[0.85,1.17]$ \\
\hline
\end{tabular}

Note: effects are reported to three decimal places where appropriate due to small effect. Continuous interactions are shown in supplementary material 1 however, the environment is represented here in quartiles and tertiles for ease of interpretation. Results were substantively the same when using a continuous exposure of the environment with a significant interaction for change in obesity and age. Parks were split into tertiles due to the granularity of the count data. 
Marginal effect of age on predicted change in obesity by PA facility availability

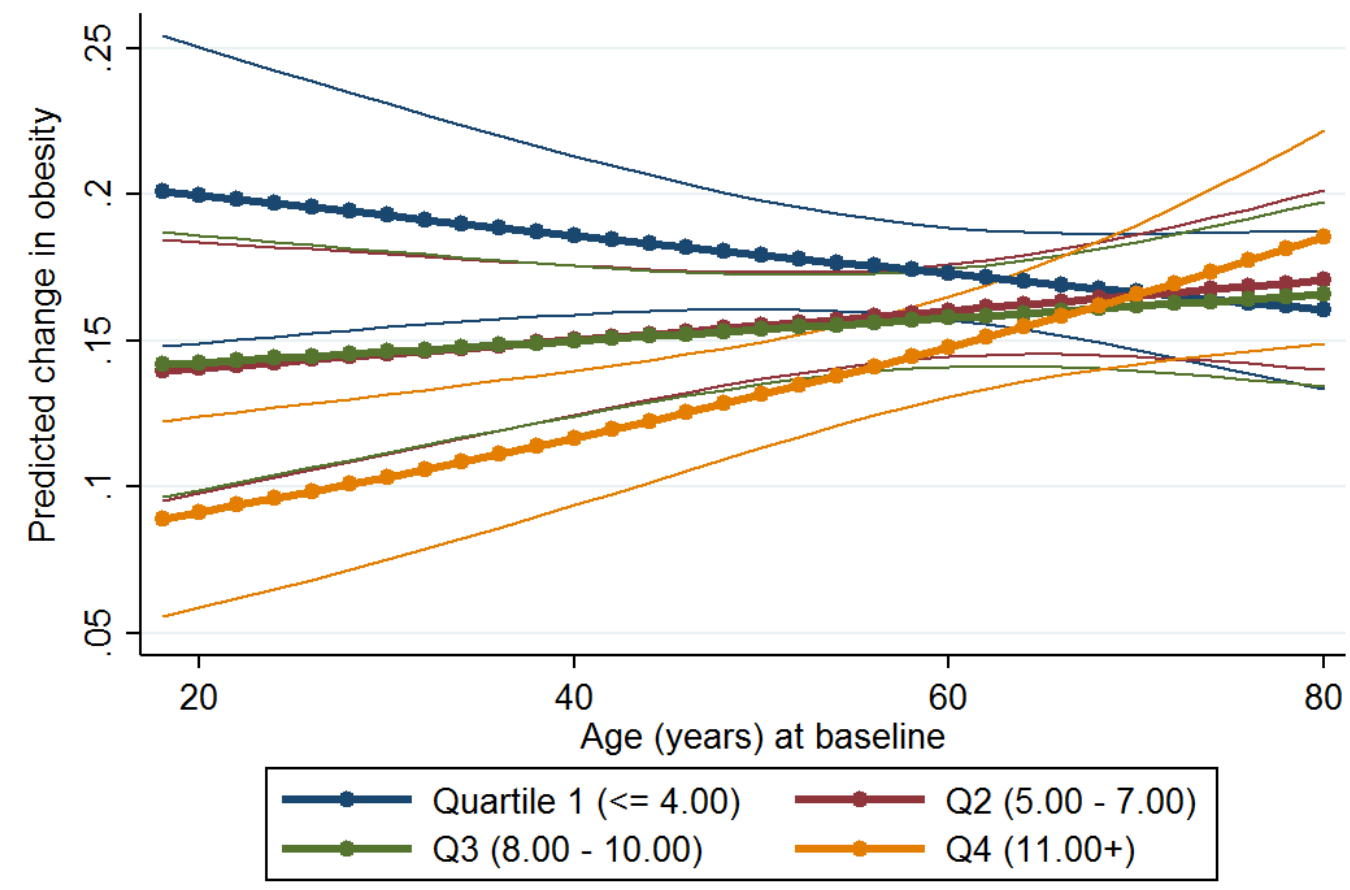

Figure 4A - PA facility availability at baseline is related to change in obesity but only for individuals with the highest availability

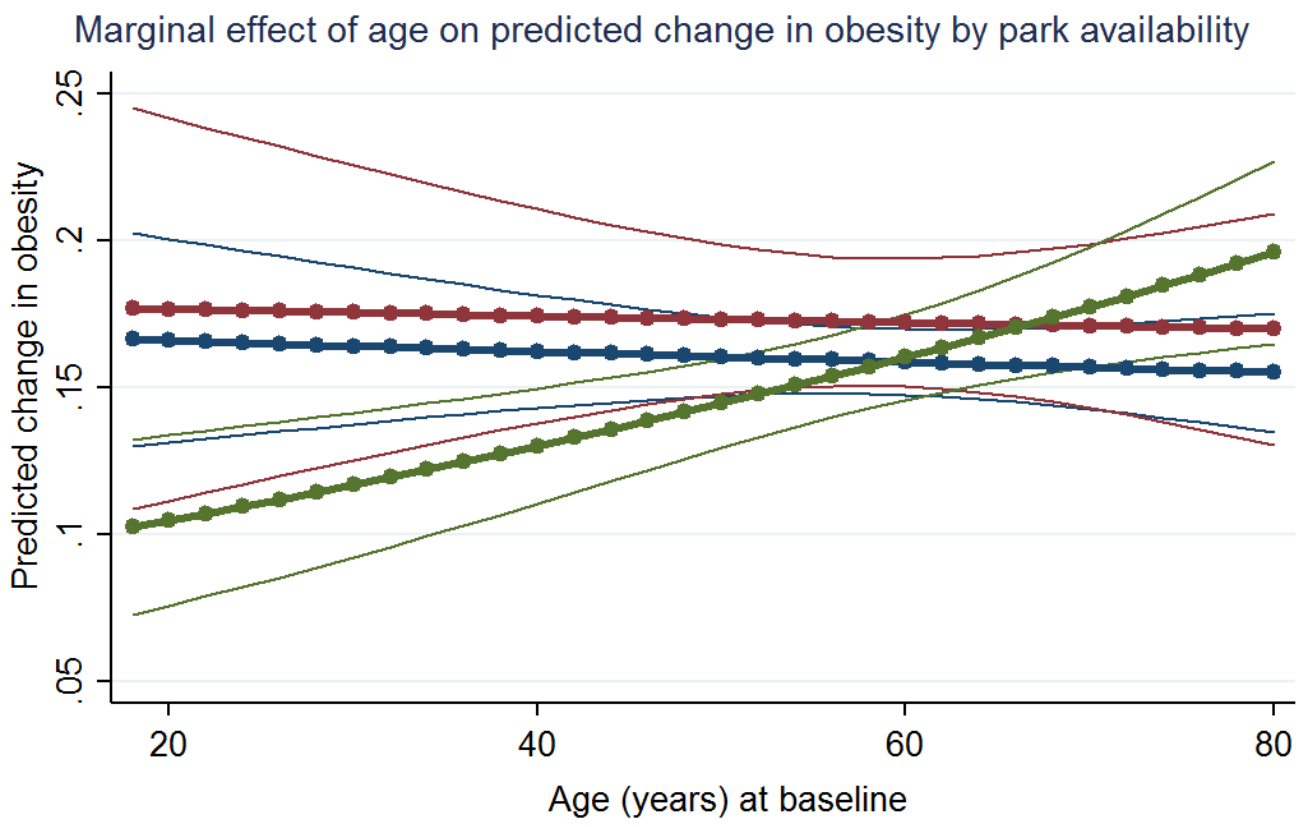

Tertile $1(<=1.00) \longrightarrow$ T2 $(2.00)$
T3 $(3.00+)$

Figure 4B - Park availability at baseline is related to change in obesity but only for individuals with the highest availability 